\title{
Spinocerebellar ataxia type 8 in Scotland: genetic and clinical features in seven unrelated cases and a review of published reports
}

\author{
A Zeman, J Stone, M Porteous, E Burns, L Barron, J Warner
}

J Neurol Neurosurg Psychiatry 2004;75:459-465. doi: 10.1136/jnnp.2003.018895

See end of article for authors' affiliations

Correspondence to:

Dr Adam Zeman

Department of Clinical

Neurosciences, University

of Edinburgh, Western

General Hospital, Crewe

Road, Edinburgh EH4

2XU, UK;

az@skull.dcn.ed.ac.uk

Received 16 May 2003

In revised form

11 July 2003

Accepted 11 July 2003

\begin{abstract}
Objectives: To establish whether the DNA expansion linked to spinocerebellar ataxia type 8 (SCA 8) is associated with ataxia in Scotland; to clarify the range of associated clinical phenotypes; and to compare the findings with previous reports.

Methods: DNA was screened from 1190 anonymised controls, 137 subjects who had tested negative for Huntington's disease, 176 with schizophrenia, and 173 with undiagnosed ataxia. Five unrelated ataxic patients with the SCA 8 expansion and a sixth identified subsequently had clinical and psychometric assessment; the clinical features were available in a seventh. A systematic search for other reports of SCA 8 was undertaken.

Results: Over $98 \%$ of SCA 8 CTA/CTG repeat lengths fell between 14 and 40. Repeat lengths over 91 were observed in three healthy controls $(0.12 \%)$, two patients with suspected Huntington's disease $(0.73 \%)$, and six ataxic subjects (1.74\%; $p<0.0005 v$ healthy controls). Repeat lengths over 100 occurred in five ataxic subjects but in only one control. All seven symptomatic subjects with the SCA 8 expansion had a cerebellar syndrome; four had upper motor neurone signs; and 5/6 assessed had cognitive complaints. There was personality change in two and mood disturbance in three. In published reports, SCA 8 repeat lengths over 91 occurred in $\sim 0.5 \%$ of the healthy population but were over-represented among ataxic patients $(3.4 \% ; \mathrm{p}<0.0001)$. The predominant clinical phenotype was cerebellar, with pyramidal signs in $50 \%$, and neuropsychiatric features in some cases.

Conclusions: SCA 8 expansion is a risk factor for a cerebellar syndrome, often associated with upper motor neurone and neuropsychiatric features. The expansion occurs unexpectedly often in the general population.
\end{abstract}

A taxia and cerebellar atrophy are the principal features of the enlarging family of dominantly inherited spinocerebellar ataxias. ${ }^{1}$ Some of these disorders also affect the retina, the peripheral nerves, the pyramidal and extrapyramidal systems, and cognitive function. SCA 1, 2, 3 , $6,7,12$, and DRPLA result from expansion of CAG trinucleotide repeats, coding for polyglutamine tracts. The pathogenic ranges of the repeat expansions giving rise to these disorders are moderately well defined. Anticipation occurs throughout this group of ataxias and is particularly associated with paternal transmission.

SCA 8, first described in $1999,{ }^{2}$ is also a trinucleotide repeat disorder, but has several distinctive features. Like myotonic dystrophy but unlike the previously described spinocerebellar ataxias, the expansion lies in a transcribed but untranslated CTG repeat on chromosome 13q21. A short polymorphic CTA repeat $(1-21 \text { CTAs })^{3}$ is located adjacent to the CTG repeat: quoted repeat lengths are usually for the CTA/CTG composite. Koob et al reported that more than $99 \%$ of a control population had 16 to 37 combined CTA/CTG repeats. ${ }^{2}$ Other trinucleotide repeats occasionally interrupt expanded CTA/ CTG trinucleotide repeat tracts. ${ }^{3}$ The CTA/CTG repeat is unstable in transmission, especially if expanded, with a tendency to expand on maternal and to contract on paternal transmission. ${ }^{2-6}$ There is also some evidence for somatic mosaicism of repeat length. ${ }^{5}$

The SCA 8 transcript, containing the CTG expansion, has been identified in brain tissue and weakly in lung, kidney, and testis. ${ }^{8}{ }^{9}$ Its most $5^{\prime}$ exon is transcribed anti-sense to the first exon of a gene coding for a novel actin binding protein, Kelch-like 1 (KLHL1). ${ }^{9}{ }^{10}$ KLHLl is primarily expressed in the cerebellum, frontal lobe, and subthalamic nucleus ${ }^{11}{ }^{12}$ - the SCA 8 transcript may modify its expression by several mechanisms. ${ }^{910}$ Comparative study in the mouse indicates that the RNA transcript containing the SCA 8 expansion has been conserved over the course of mammalian evolution. ${ }^{9}$

In the large family reported by Koob et al, MN-A, CTA/CTG repeat lengths in affected individuals ranged from 110 to 130 (107 to 127 CTG repeats). ${ }^{2}$ The phenotype was typical of the SCA group, consistently involving cerebellar ataxia with variable limb spasticity and impaired vibration sense. It was linked to the SCA 8 expansion on $13 \mathrm{q} 21$ with a highly significant lod score of 6.8. The penetrance of the expansion was low, however, with ataxia in only 13 of 35 carriers of the expansion. CTG repeat lengths were significantly greater among affected than unaffected carriers (116 v90).

We have previously described a mother and son with the SCA 8 expansion, ${ }^{13}$ mild cerebellar ataxia, cognitive and psychiatric symptoms, and signs of a dysexecutive ("frontal lobe") disorder, raising the possibility that the phenotype of the disorder is wider than first envisaged. In addition, since Koob's original paper, several reports have cast doubt on the validity of the SCA 8 syndrome given that the SCA 8 expansion occurs surprisingly often among apparently healthy individuals in some control populations. ${ }^{6}{ }^{14-17}$

Abbreviations: ACE, Addenbrooke's cognitive examination; DSM-IV, Diagnostic and Statistical Manual of Mental Diseases, $4^{\text {th }}$ edition; HADS, hospital anxiety and depression scale; MMSE, mini-mental state examination 
In an effort to reduce the uncertainties surrounding the diagnosis of SCA 8 we have addressed the following questions. First, is the SCA 8 expansion associated with ataxia in our own ataxic and control populations? Second, what is the range of clinical phenotypes associated with the expansion? Specifically, is the expansion associated with neuropsychological or neuropsychiatric features? And third, do our findings agree with the results of a systematic review of published reports?

\section{METHODS}

\section{Subjects}

Leucocyte DNA from the following groups was screened for the SCA 8 expansion:

- 1190 anonymised healthy controls;

- 137 patients undergoing investigation for possible Huntingtons' disease with a negative result;

- 176 patients with schizophrenia;

- 173 patients with undiagnosed ataxic syndromes, in whom the expansions associated with spinocerebellar ataxias $1,2,3,6,7$, or DRPLA had been excluded.

We assessed the five subjects with the SCA 8 expansion (combined CTA/CTG repeats >100) identified among the ataxic group above (one of these, patient 5 , was the case we had reported previously). Two further ataxic patients with CTA/CTG repeats $>100$ were identified in the course of routine clinical testing; one has been fully assessed and limited clinical details are available for the second.

\section{DNA analysis}

All DNAs were amplified with the original primers SCA 8-1 and SCA 8-2 using the published method. ${ }^{2}$ One of the primers ( SCA 8-2) was 5' FAM labelled and all products were resolved on a high resolution polyacrylamide/urea gel on an automatic sequencer. Specimens that appeared homozygous on the sequencer were reamplified with primers SCA 8-2 and SCA 8-3 (TGC TGC TGC TGC TGC ATT TTT TAA) which produce a characteristic ladder of fragments with a $3 \mathrm{bp}$ periodicity in the presence of a large repeat.

\section{Clinical assessment}

A consultant neurologist and consultant clinical geneticist took a structured clinical history from each of the six subjects who underwent full assessment, and carried out a standard neurological examination. The seventh subject was assessed by another consultant neurologist in a routine clinical setting.

\section{Cognitive assessment}

This comprised the mini-mental state examination (MMSE) ${ }^{18}$ and the Addenbrooke's cognitive examination (ACE). ${ }^{19}$

\section{Psychiatric assessment}

Subjects were assessed with the structured clinical interview for DSM-IV axis I disorders, ${ }^{20}$ such as depression, anxiety, and psychosis. The hospital anxiety and depression scale $(\mathrm{HADS})^{21}$ was used to obtain dimensional ratings of current mood disorder.

\section{Radiology}

Magnetic resonance imaging (MRI) findings were reviewed in all patients.

\section{Review of published reports}

We reviewed all available published reports on SCA 8 ascertained by a Medline search (1996 to March 2003), using the search terms "SCA8", "SCA 8", and "spinocerebellar ataxia type 8 ", by inspection of the OMIM SCA 8 site, ${ }^{22}$ and by obtaining all relevant papers referred to in those produced by the original search. The papers were reviewed and data abstracted by two of us independently. Points of disagreement were discussed and resolved by referring back to the papers.

\section{Statistics}

We analysed differences between the proportions of patients heterozygous for a SCA8 expansion of greater than 91 CTA/ CTG repeats among ataxic patients, in the control groups represented in the current study, and in summary data obtained from the literature review. Analysis was carried out using Fisher's exact test. Odds ratios and their 95\% confidence intervals were calculated using StatsDirect (www.statsdirect.com).

\section{RESULTS}

\section{Current series}

Prevalence of the SCA 8 expansion

These results are shown in table 1 and fig 1 . Over $98 \%$ of SCA $8 \mathrm{CTA} / \mathrm{CTG}$ combined repeat lengths in all four groups fell between 14 and 40 . Repeats of greater than 91 were seen in $3.5 \%$ of the ataxic group ( six unrelated subjects), $0.3 \%$ of the anonymised control group (three subjects, $\mathrm{p}<0.0005$ ), $1.5 \%$ of the Huntington's control group (two subjects, NS), and none of the schizophrenia control group $(\mathrm{p}<0.05)$. Repeats over 100 were seen in five ataxic patients, but in only one patient from the three control groups-an anonymised healthy control $(p<0.0001)$. Comparison of all controls with ataxic subjects yielded an odds ratio of 10.8 (95\% confidence interval 2.7 to 45.0 ) for an SCA 8 CTA/CTG combined repeat length greater than 91 among ataxic subjects.

\section{Clinical features}

The clinical features are summarised in table 2 .

\section{Demographics}

Our subjects developed symptoms at ages ranging from 13 to 47 years. Five are female, two male. Three subjects gave a family history of a similar disorder. Patient 5, described in our previous report, ${ }^{13}$ had a similarly affected mother whom we have examined. Patient 6 had an apparently similarly affected, now deceased, father; three of her father's siblings have neurological diagnoses, although we are uncertain of the grounds for these (one "Parkinson's disease", one "motor neurone disease", one "Parkinson's disease or motor neurone disease"). Patient 7 has a similarly affected brother. All patients had been screened carefully for other causes of ataxia.

\section{Presenting symptoms-neurological}

Gait disturbance was a prominent symptom in all our patients. Four complained of dysarthria, two of dysphagia; four reported motor symptoms in the limbs other than gait disorder, two urinary urgency, and one sensory disturbance. One patient had developed torticollis. Three complained of Raynaud's phenomenon.

Presenting symptoms - cognitive and psychiatric These were assessed systematically in patients 1-6. Five patients had cognitive complaints at presentation. The academic performance of patient 4 declined markedly at the time of his personality change, in his early teens, described below. Personality change was a prominent feature in two of our patients (4 and 5), preceding the onset of cerebellar features in patient 4 by about four years. In patient 4 the change involved loss of interest in other people, loss of empathy, decline of interpersonal skills, and loss of enthusiasm for hobbies. Patient 5 became irritable, inflexible, and 
Table 1 SCA8 CTA/CTG repeat sizes among patients with ataxia and three control groups

\begin{tabular}{|c|c|c|c|c|c|c|c|}
\hline \multirow[b]{2}{*}{ Subjects } & \multirow[b]{2}{*}{$\mathbf{N}$} & \multicolumn{5}{|c|}{ No of patients heterozygous for each category of SCA8 CTA/CTG repeat size (\%)* } & \multirow[b]{2}{*}{ Significance ${ }^{* *}$} \\
\hline & & $14-40$ & $40-90$ & $91-100$ & $>100$ & $>91$ & \\
\hline Ataxia & 173 & $167(96.5 \%)$ & 0 & $1(0.58 \%)$ & $5(2.9 \%)$ & $6(3.47 \%)$ & - \\
\hline Anonymised healthy controls & 1190 & $1178(99.0 \%)$ & $9(0.76 \%)$ & $2(0.17 \%)$ & $1(0.08 \%)$ & $3(0.25 \%)$ & $\mathrm{p}<0.0005$ \\
\hline ? Huntington's disease & 137 & $132(96.4 \%)$ & $3(2.2 \%)$ & $2(1.46 \%)$ & 0 & $2(1.46 \%)$ & NS \\
\hline Schizophrenia & 176 & $175(99.4 \%)$ & $1(0.6 \%)$ & 0 & 0 & $0(0 \%)$ & $p<0.05$ \\
\hline All controls & 1503 & $1485(98.8 \%)$ & $13(0.86 \%)$ & $4(0.27 \%)$ & $1(0.07 \%)$ & $5(0.33 \%)$ & $p<0.0005$ \\
\hline
\end{tabular}

*No patient was homozygous for the SCA8 expansion.

**All comparisons against ataxic group using a repeat size greater than 91 and Fisher's exact test.

routine bound. Mood disturbance or lability was prominent in patients 2, 3, and 6. This was particularly marked in patient 6 who reported several episodes of uncontrolled laughter and crying.

\section{Neurological signs}

All subjects had clinical signs of cerebellar involvement, except possibly for patient 6 , in whom prominent upper and lower motor neurone signs complicated the interpretation of her limb ataxia and gait disturbance. Four patients had clear evidence of pyramidal tract dysfunction, with equivocal evidence in a fifth (patient 5). There were minor sensory features in three patients. Patient 6 was unusual in displaying some lower motor neurone signs: wasting and weakness in the hands, weakness of ankle plantar flexion, and absence of the ankle jerks in the face of pathologically brisk reflexes in the arms.

\section{Cognitive examination}

Screening with the MMSE and ACE did not reveal evidence of dementia in any of the patients. These tests are insensitive to subtle neuropsychological deficits and executive dysfunction, which we had previously demonstrated in patient 5 . However, the tests exclude gross cognitive impairment.

\section{Psychiatric examination}

Two patients gave histories of past major depression and panic disorder (patients 1 and 2). In both patients these disorders occurred soon after the onset of ataxia. Patient 3 had current obsessive-compulsive disorder, with onset four years after her first neurological symptoms: she reported a time consuming obsession with even numbers, for example counting her footsteps to make sure that they summed to an even number, buying even numbers of cans, and chopping even numbers of vegetables. The results on the HADS indicated that none of the patients was significantly anxious or depressed at the time of testing. No subjects had a personality disorder.

\section{Radiology}

Brain MRI revealed cerebellar atrophy in five of the seven patients. In patient 2 an initial scan in 1996 had been reported as normal, but by 2000 a second scan showed clear cut cerebellar atrophy (fig 2). In retrospect the 1996 scan showed borderline changes, with enlargement of the fourth ventricle. No other significant changes were noted in the scans.

\section{Review of published reports}

The prevalence and range of the SCA 8 expansion

Table 3 compares the frequency of SCA 8 expansions $>91$ combined CTA/CTG repeats in unrelated patients with undiagnosed ataxia with the frequency among healthy and pathological controls in all published series. We have not included cases in which there was a plausible alternative explanation for the ataxia or ataxic cases with SCA 8

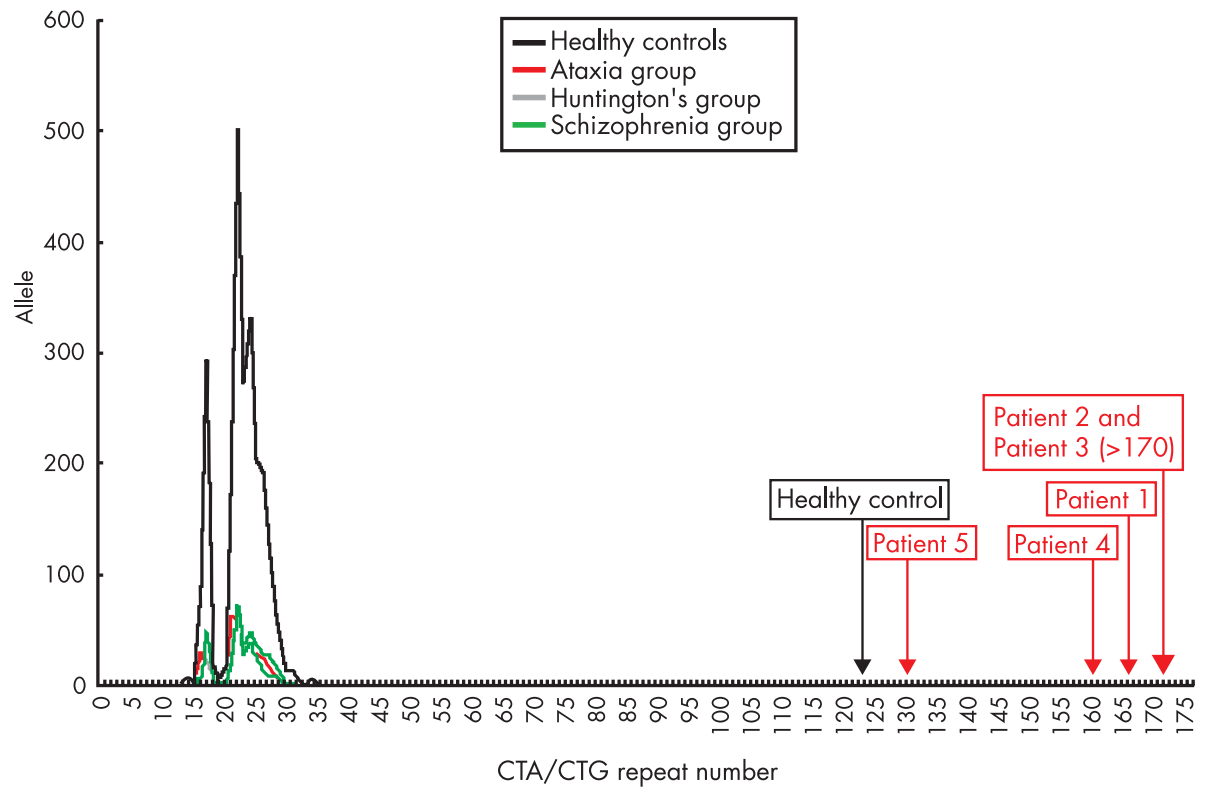

Figure 1 Combined CTA/CTG repeat frequencies in healthy controls, ataxic subjects, subjects who tested negative for Huntington's disease, and subjects with schizophrenia. The five patients and single control subject with repeat lengths of $>100$ are indicated (patients 6 and 7 were identified subsequently in the course of clinical testing). 
Table 2 SCA 8 patients: demographic details, repeat lengths, MRI findings, and clinical features

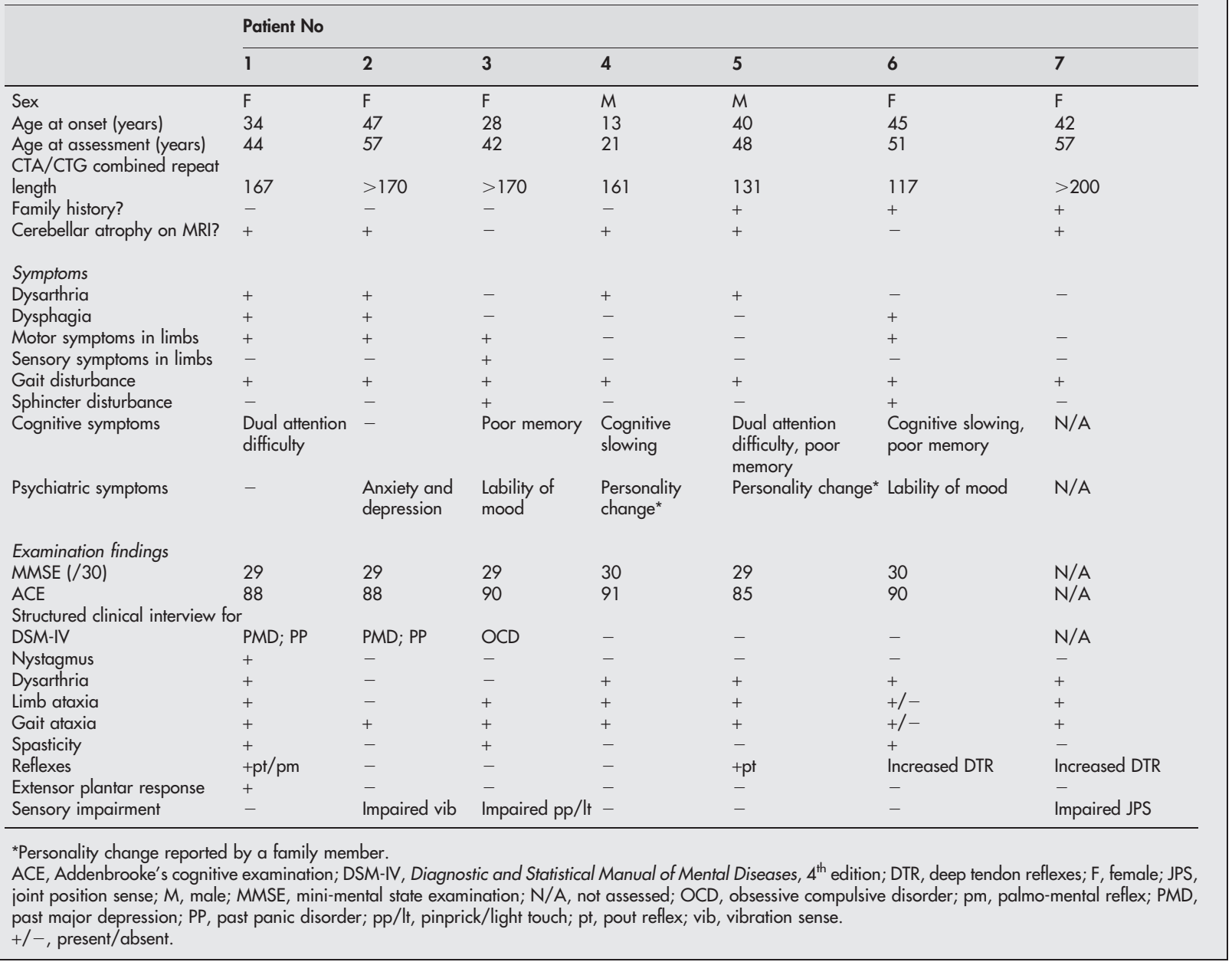

expansions of $<91$ CTA/CTG repeats. (Our choice of 91 repeats as a cut off value is discussed further below.) Table 3 shows that combined CTA/CTG repeats over 91 occur significantly more often among patients with undiagnosed ataxia $(3.4 \%)$ than among all controls $(0.7 \%)$, healthy controls $(0.54 \%)$, psychiatric controls $(1.2 \%)$, and controls with other neurological disorders $(0.8 \%) \quad(\mathrm{p}<0.0001$ for all comparisons, Fisher's exact test). Cases with a family history were more likely than sporadic cases to have an expansion greater than $91 \quad(p<0.01)$. Comparing all controls with ataxic subjects yielded an odds ratio of 5.0 (95\% confidence interval, 3.5 to 7.2 ) for an SCA 8 CTA/CTG combined repeat length of greater than 91 among ataxic subjects. The data suggest geographical variation in population frequencies of the expansion; for example, Juvonen et al reported control and ataxic population frequencies of $2.9 \%$ and $8.8 \%$, respectively, in Finland, ${ }^{24}$ while Sasaki et al failed to identify a single SCA 8 expansion among 344 patients with familial ataxia in Japan. ${ }^{25}$

Expansion lengths among affected individuals range from 81 to 800 . However, only four affected patients in the literature have repeat expansions between 81 and 91,7 151630 and only four have expansions over $300 .{ }^{17}{ }^{24}$ The great majority of symptomatic expansions fall between 91 and 200. Ten unaffected healthy controls with very large expansions $(>300)$ have been described. ${ }^{6} 163031$

Penetrance of the expansion and transmission within SCA 8 families

The limited data available suggest that the penetrance of the SCA expansion among carriers within affected families is around 50\% (35 of 64 subjects). ${ }^{25} 151627-30$ Koob et al reported that within their large family repeat lengths were greater in affected than unaffected carriers of the expansion. ${ }^{2}$ There is a tendency for the CTA/CTG repeat to expand on maternal and contract on paternal transmission. ${ }^{25}{ }^{5}$ However, most series document cases with paternal transmission.

\section{Clinical features of the SCA 8 expansion}

The clinical features of SCA 8 expansion are summarised in table 4 . The most common and obvious manifestation of the SCA 8 phenotype is a cerebellar syndrome, with gait ataxia in almost all patients, and limb incoordination and dysarthria in the majority. About half the patients develop upper motor neurone signs. Lower motor neurone signs, bladder disturbance, and sensory symptoms occur in a few. Published reports indicate that cognitive features can occur. These are more prominent in patients with onset in childhood or adolescence, $^{530}$ sometimes amounting to dementia, ${ }^{30}$ although to date there are no group studies of patients with SCA 8 detailing the results of neuropsychological assessment. The possibility has been raised that rates of the SCA 8 expansion may be increased in patients with psychiatric diagnoses..$^{30}$ Our review indicates that the likelihood of an SCA8 expansion is higher in psychiatric samples than in healthy controls $(p=0.02)$. However, there have been no systematic reports of neuropsychiatric features to date. Myoclonic epilepsy occurred in one patient with onset in the first year of life. ${ }^{5}$ One series has reported consistent abnormalities on neurophysiological testing, ${ }^{4}$ but other studies have not detected these (table 4). The reported ages of onset range from the first year of life to 65 . The majority of cases have onset in early to mid adulthood. Progression of the 


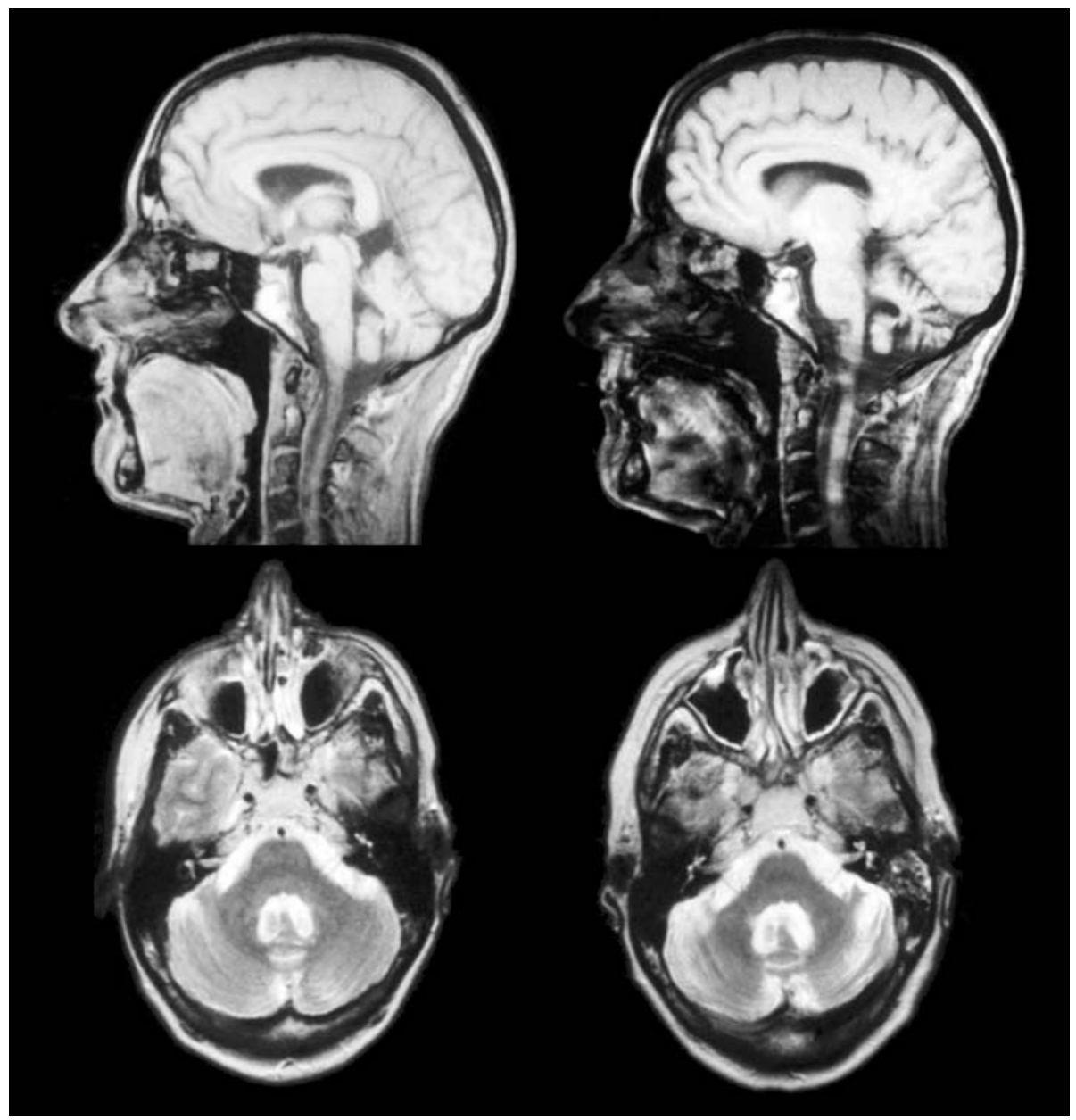

Figure 2 Magnetic resonance imaging of the brain in patient 2 in 1996 (left) and 2000 (right), showing progression from borderline cerebellar atrophy in 1996 to marked atrophy in 2000.

disorder is slow and severity highly variable. Some cases have come to light only on neurological assessment. In Koob's original family, "severely affected family members were nonambulatory by the fourth to sixth decade." ${ }^{2}$ It is unclear whether the size of the repeat expansion influences the age of onset or severity of the disorder. ${ }^{16}{ }^{30}$

\section{DISCUSSION}

\section{Is the "SCA8 expansion" associated with ataxia?}

While Koob's original observations ${ }^{2}$ appeared to prove that the SCA 8 expansion could cause an ataxic syndrome, subsequent reports indicated an unexpectedly high rate of repeat expansions in unaffected controls. The data summarised in table 3 clarify the relation between the SCA 8 expansion and ataxia. The expansion is common among unaffected controls, occurring in around $0.5 \%$. However, it is significantly more common among unrelated patients with unexplained ataxia, particularly among those with a family history of ataxia, showing that there is an association between the SCA 8 expansion and ataxia. The high background rate among controls suggests that the expansion may best be regarded as a risk factor for ataxia which only gives rise to disease in the presence of some other factor or factors, discussed below.

What is the pathogenic range of the SCA 8 expansion? The great majority of patients with SCA 8 have combined CTA/CTG repeat expansions in the range 91 to 200. We chose the cut off of 91 combined CTA/CTG repeats in table 3 somewhat arbitrarily-this was the upper end of the control range identified by Koob et al in their original paper, and it was possible to extract the frequencies of repeats above and below this value from the other published series. The published data suggest that a small number of subjects with repeats in the 80 s are symptomatic, as are a small number with repeats over 200. It has been suggested that very large expansions may be transcriptionally silent and therefore unlikely to cause disease. ${ }^{31}$

\section{What is the SCA 8 phenotype?}

SCA 8 causes cerebellar ataxia almost invariably, upper motor neurone signs commonly, and lower motor neurone signs, sensory features, and bladder disturbance occasionally. Our data suggest that cognitive and psychiatric symptoms occur quite commonly. We have not demonstrated objective cognitive impairment in our patients, but the screening tests reported here are insensitive to subtle changes in cognitive function of the kind we have described previously in a single family..$^{13}$ The variation in the reported rates of cognitive and psychiatric features in published series may well reflect varying approaches to assessment. Marked cognitive decline occurs in some patients, and is particularly common in cases with onset in childhood or adolescence. This could reflect the observation that the KLHLl protein plays a more active role in the developing brain than in the adult brain, ${ }^{10}$ the role of the cerebellum in cognitive development, ${ }^{34}$ or both. Cognitive impairment is more often observed in early than in late onset 
Table 3 The prevalence of the SCA 8 expansion (>91 CTA/CTG repeats) in unrelated patients with undiagnosed ataxia and controls

\begin{tabular}{|c|c|c|c|c|c|c|c|}
\hline \multirow[b]{2}{*}{ Series } & \multicolumn{4}{|c|}{ Control subjects } & \multicolumn{3}{|c|}{ Ataxic subjects (' $\mathrm{f}^{\prime}=$ number of familial cases) } \\
\hline & $>91$ repeats & Sample size & Type of control group & Significance† & $>91$ repeats & Sample size & Comments \\
\hline Koob $^{2}$ & 0 & 600 & Healthy & & $7(7 f)$ & 209 (209f) & \\
\hline Silveira ${ }^{5}$ & 0 & 909 & Healthy & & $5(5 f)$ & $73(73 f)$ & \\
\hline Ikeda $^{7}$ & 0 & 52 & Healthy & & $4(2 f)$ & $63(22 f)$ & \\
\hline \multirow[t]{2}{*}{ Stevanin $^{14}$} & 3 & 188 & Healthy & & $8(7 f)$ & $250(174 f)$ & \\
\hline & 2 & 46 & $\begin{array}{l}\text { Other neurological } \\
\text { disorder }\end{array}$ & & & & \\
\hline Worth ${ }^{15}$ & 5 & 653 & Mixed* & & $3(2 f)$ & 264 (119f) & \\
\hline Vincent $^{6} 23$ & 5 & 916 & Healthy & & & & \\
\hline \multicolumn{8}{|l|}{ Vincent, personal } \\
\hline communication & 19 & 1359 & Psychiatric & & & & \\
\hline Juvonen $^{24}$ & 13 & 448 & Healthy & & 22 (13f) & $251(86 f)$ & \\
\hline Sasaki $^{25}$ & & & & & 0 & $42(42 f)$ & \\
\hline Sobrido $^{17}$ & 1 & 112 & Alzheimer's & & $2(1 f)$ & 135 (50f) & \\
\hline \multirow[t]{2}{*}{ Cellini $^{26}$} & 0 & 161 & Healthy & & $1(1 \mathrm{f})$ & 113 (50f) & \\
\hline & 0 & 125 & Psychiatric & & & & \\
\hline Brusco $^{27}$ & 0 & 127 & Healthy & & $2(2 f)$ & $134(22 f)$ & \\
\hline Tazon $^{28}$ & 1 & 149 & Healthy & & $3(3 f)$ & 75 (19f) & \\
\hline \multirow[t]{3}{*}{ Topisirovic ${ }^{29}$} & 0 & 125 & Healthy & & 1 (Of) & 115 (91f) & \\
\hline & 0 & 64 & $\begin{array}{l}\text { Other neurological } \\
\text { disorder }\end{array}$ & & & & \\
\hline & 0 & 70 & Schizophrenia & & & & \\
\hline \multirow[t]{3}{*}{ Izumi ${ }^{30}$} & 3 & 327 & Healthy & & $13(5 f)$ & 362 (119f) & \\
\hline & 0 & 158 & Alzheimer's & & & & \\
\hline & 1 & 224 & Parkinson's & & & & \\
\hline \multirow[t]{3}{*}{ Zeman (this study) } & 3 & 1190 & Healthy & & 6 & 173 & Proportion of familial cases in \\
\hline & 2 & 137 & ?Huntington's disease & & & & ataxic patients without SCA8 \\
\hline & 0 & 176 & Schizophrenia & & & & expansion unknown \\
\hline \multirow[t]{4}{*}{ Subtotals } & 28 & $5192(0.54 \%)$ & Healthy & $\mathrm{p}<0.0001$ & $48(4.46 \%)$ & 1076 & All familial cases ${ }^{* *}$ \\
\hline & 19 & $1730(1.16 \%)$ & Psychiatric & $\mathrm{p}<0.0001$ & $23(2.28 \%)$ & 1010 & All sporadic cases ${ }^{* *}(p<0.01$ \\
\hline & 6 & $741(0.81 \%)$ & $\begin{array}{l}\text { Other neurological } \\
\text { disorder }\end{array}$ & $\mathrm{p}<0.0001$ & & & familial $v$ sporadic) \\
\hline & 5 & $653(0.92 \%)$ & Mixed* & & & & \\
\hline Totals & 58 & $8316(0.70 \%)$ & All controls & $\mathrm{p}<0.0001$ & 77 (3.41\%) & 2259 & $\begin{array}{l}\text { All cases of undiagnosed } \\
\text { ataxia }\end{array}$ \\
\hline
\end{tabular}

myotonic dystrophy, ${ }^{30}$ another genetic disorder caused by a transcribed but untranslated CTG repeat expansion.

Why is the penetrance of the SCA 8 expansion low? The SCA 8 expansion is of low penetrance in two distinct senses: first, the data from healthy controls indicate that the majority of carriers of the expansion in the general population do not have ataxia. Indeed, assuming a rough prevalence of 1:100 000 for ataxia resulting from SCA $8,{ }^{325}$ and given that the expansion is present in around one in 200 of the population, only about one in 500 individuals with the
SCA 8 expansion is likely to manifest the disease. Second, although the risk that a carrier will show ataxia is much increased within symptomatic families (to around 50\%), many carriers in affected families never manifest the disease. Several factors may help to explain these findings, but their relative importance is unclear: effects of the CTA/CTG ratio or interruptions within the repeat sequence; somatic mosaicism; the presence of modifying alleles elsewhere in the genome, including co-occurrence of other SCA mutations ${ }^{30}$; other epigenetic factors; late emergence of symptoms in subjects within affected families; and the presence of subtle but

Table 4 Clinical features reported previously in SCA 8

\begin{tabular}{|c|c|c|c|c|c|c|c|c|c|}
\hline & \multicolumn{4}{|c|}{ Cerebellar signs } & \multicolumn{2}{|l|}{ Pyramidal signs } & \multirow[b]{2}{*}{ Sensory signs } & \multirow[b]{2}{*}{$\begin{array}{l}\text { Cognitive } \\
\text { impairment }\end{array}$} & \multirow[b]{2}{*}{$\begin{array}{l}\text { Neurophysiologica } \\
\text { abnormality }\end{array}$} \\
\hline & Nystagmus & Dysarthria & Limb ataxia & Gait ataxia & Hyperreflexia & $\begin{array}{l}\text { Extensor } \\
\text { plantar }\end{array}$ & & & \\
\hline Day $^{4}$ & $8 / 11$ & $11 / 11$ & $11 / 11$ & $10 / 11$ & $8 / 11$ & $2 / 11$ & $5 / 11$ & $0 / 11$ & $7 / 7$ \\
\hline lkeda ${ }^{7}$ & $4 / 6$ & $6 / 6$ & $6 / 6$ & $6 / 6$ & $1 / 6$ & $0 / 6$ & $2 / 6$ & $0 / 6$ & - \\
\hline Silveira ${ }^{5}$ & - & $7 / 7$ & & $6 / 7$ & - & - & - & $3 / 7$ & - \\
\hline Juvonen ${ }^{16}$ & $5 / 15$ & $14 / 15$ & $12 / 15$ & $13 / 15$ & $9 / 15$ & $5 / 15$ & $4 / 15$ & $6 / 15$ & - \\
\hline $\operatorname{Jardim}^{32}$ & $1 / 1$ & $1 / 1$ & $1 / 1$ & $1 / 1$ & $0 / 1$ & $0 / 1$ & $1 / 1$ & $0 / 1$ & - \\
\hline Sempere ${ }^{33}$ & $0 / 1$ & $1 / 1$ & $1 / 1$ & $1 / 1$ & $1 / 1$ & $0 / 1$ & $0 / 1$ & & $0 / 1$ \\
\hline Brusco $^{27}$ & $2 / 4$ & $3 / 4$ & $3 / 4$ & $4 / 4$ & $2 / 4$ & $2 / 4$ & $1 / 4$ & $0 / 4$ & $0 / 1$ \\
\hline Topisirovic $^{29}$ & - & $1 / 1$ & $1 / 1$ & $1 / 1$ & $1 / 1$ & - & - & $0 / 1$ & $0 / 1$ \\
\hline$T^{T a z o n}{ }^{28}$ & $2 / 3$ & $3 / 3$ & $3 / 3$ & $3 / 3$ & - & $0 / 2$ & $0 / 2$ & $0 / 1$ & $0 / 3$ \\
\hline Izumi $^{30}$ & - & & - & $15 / 15$ & $9 / 15$ & $1 / 15$ & & $4 / 15$ & - \\
\hline Zeman* & $1 / 7$ & $5 / 7$ & $6 / 7$ & $7 / 7$ & $4 / 7$ & $1 / 7$ & $3 / 7$ & $5 / 7$ & - \\
\hline Total & $23 / 48$ & $52 / 56$ & $44 / 49$ & $67 / 71$ & $35 / 61$ & $11 / 62$ & $16 / 45$ & $18 / 68$ & $7 / 13$ \\
\hline Total (\%) & $48 \%$ & $93 \%$ & $90 \%$ & $94 \%$ & $57 \%$ & $18 \%$ & $36 \%$ & $26 \%$ & $54 \%$ \\
\hline
\end{tabular}


unnoticed symptoms and signs-neurological, cognitive or psychiatric-among "healthy" controls.

\section{Is SCA 8 an example of the cognitive-affective cerebellar syndrome?}

Schmahman has drawn attention to the occurrence of cognitive and affective change in patients with focal cerebellar lesions. ${ }^{35}$ Anatomical findings and functional imaging also suggest that the cerebellum contributes to cognition. It is possible that the cognitive and psychiatric features of SCA 8, and other spinocerebellar ataxias, reflect this contribution. However, it is likely that the molecular pathology of SCA 8 and other spinocerebellar ataxias extends beyond the cerebellum-for example, into the frontal lobes and basal ganglia. ${ }^{11}$ This more extensive cerebral involvement, rather than cerebellar pathology of its own, may well be the explanation for the cognitive and affective features of SCA 8.

\section{Should the SCA 8 probe be used in routine diagnostic practice?}

We agree with the conclusion of Juvonen et al, ${ }^{24}$ that DNA analysis for the SCA 8 expansion is a helpful test in patients with otherwise unexplained ataxia. Their data suggested that the predictive value of an expansion length of between 80 and 800 repeats for the diagnosis of SCA 8 was $68 \%$ overall among patients with ataxia, rising to $86 \%$ in patients with a family history of dominantly inherited ataxia, and falling to $47 \%$ among those with sporadic ataxia. It is noteworthy, however, that these predictive values are significantly lower than those usually provided by diagnostic tests in clinical genetics. A positive result should not discourage a thorough search for other causes of ataxia. Moreover, testing for SCA 8 is of no value in asymptomatic subjects in the general population, and should not be used as a predictive test in asymptomatic individuals within families affected by SCA 8 . However, our laboratory's growing experience of the probe indicates that SCA 8 is the second most commonly identified genetic association of ataxia in our population, after SCA 6 .

\section{ACKNOWLEDGEMENTS}

We are very grateful to the patients for participating; to Professors Warlow and Will and Drs Grant and Lueck for referring their patients; and to Dr John Vincent and Dr Michael Koob for their help and their comments on the paper. AZ is supported by a PPP Foundation mid-career award.

\section{Authors' affiliations}

A Zeman, J Stone, E Burns, Department of Clinical Neurosciences, University of Edinburgh, Western General Hospital, Edinburgh, UK M Porteous, L Barron, J Warner, Department of Clinical Genetics, University of Edinburgh

Competing interests: none declared

\section{REFERENCES}

1 Bird TD. Hereditary ataxia overview. WWW, 1-22. 27-2-2003.

2 Koob MD, Moseley ML, Schut $\sqcup$, et al. An untranslated CTG expansion causes a novel form of spinocerebellar ataxia (SCA8). Nat Genet 1999;21:379-84.

3 Moseley ML, Schut $\sqcup$, Bird TD, et al. SCA8 CTG repeat: en masse contractions in sperm and intergenerational sequence changes may play a role in reduced penetrance. Hum Mol Genet 2000;9:21 25-30.

4 Day JW, Schut $\amalg$, Moseley ML, et al. Spinocerebellar ataxia type 8: clinical features in a large family. Neurology 2000;55:649-57.
5 Silveira I, Alonso I, Guimaraes L, et al. High germinal instability of the (CTG)n at the SCA8 locus of both expanded and normal alleles. Am J Hum Genet 2000;66:830-40

6 Vincent JB, Neves-Pereira ML, Paterson AD, et al. An unstable trinucleotiderepeat region on chromosome 13 implicated in spinocerebellar ataxia: a common expansion locus. Am J Hum Genet 2000;66:819-29.

7 lkeda $Y$, Shizuka M, Watanabe $M$, et al. Molecular and clinical analyses of spinocerebellar ataxia type 8 in Japan. Neurology 2000;54:950-5.

8 Janzen MA, Moseley ML, Benzow KA, et al. Limited expression of SCA 8 is consistent with cerebellar pathogenesis and toxic gain of function RNA model [abstract]. Am J Hum Genet 1999;65:A276.

9 Benzow KA, Koob MD. The KLHL1-antisense transcript is evolutionarily conserved. Mammalian Genome 2003;13:134-41.

10 Nemes JP, Benzow KA, Moseley ML, et al. The SCA8 transcript is an antisense RNA to a brain-specific transcript encoding a novel actin-binding protein (KLHL1). Hum Mol Genet 2000;9:1543-51.

11 Koob MD, Moseley ML, Benzow KA, et al. The Sca8 transcript is antisense RNA to a brain-specific transcript encoding a novel actin-binding protein (KLH1) [abstract]. Am J Hum Genet 1999;65:A30.

12 Nagase T, Kikuno R, Ishikawa K, et al. Prediction of the coding sequences of unidentified human genes. XVII. The complete sequence of 100 new cDNA clones from brain which code for large proteins in vitro. DNA Res 2000;7:143-50.

13 Stone J, Smith L, Watt K, et al. Incoordinated thought and emotion in spinocerebellar ataxia type 8 . J Neurol 2001;248:229-32.

14 Stevanin G, Herman A, Durr A, et al. Are (CTG)n expansions at the SCA8 locus rare polymorphisms? Nat Genet 2000;24:213

15 Worth PF, Houlden H, Giunti P, et al. Large, expanded repeats in SCA8 are not confined to patients with cerebellar ataxia. Nat Genet 2000;24:214-15.

16 Juvonen V, Hietala $M$, Paivarinta $M$, et al. Clinical and genetic findings in Finnish ataxia patients with the spinocerebellar ataxia 8 repeat expansion. Ann Neurol 2000;48:354-61.

17 Sobrido MJ, Cholfin JA, Perlman S, et al. SCA8 repeat expansions in ataxia: a controversial association. Neurology 2001;57:1310-12.

18 Folstein MF, Folstein SE, McHugh PR. "Mini-mental state". A practical method for grading the mental state of patients for the clinician. J Psychiatr Res 1975; 12:189-98.

19 Mathuranath PS, Nestor PJ, Berrios GE, et al. A brief cognitive test battery to differentiate Alzheimer's disease and frontotemporal dementia. Neurology 2000;55:1613-20.

20 First MB, Spitzer RL, Gibbon M, et al. Structured clinical interview for DSM-IVTR axis I disorders, research version, patient edition (SCID-I/P). New York: Biometrics Research, New York State Psychiatric Institute, 2001

21 Zigmond AS, Snaith RP. The hospital anxiety and depression scale. Acta Psychiatr Scand 1983;67:361-70.

22 Spinocerebellar ataxia 8. OMIM, 1-7. 22-2-2003.

23 Vincent JB, Yuan QP, Schalling $M$, et al. Long repeat tracts at SCA8 in major psychosis. Am J Med Genet 2000;96:873-6.

24 Juvonen V, Kairisto V, Hietala $M$, et al. Calculating predictive values for the large repeat alleles at the SCA8 locus in patients with ataxia. J Med Genet 2002;39:935-6.

25 Sasaki H, Yabe I, Yamashita l, et al. Prevalence of triplet repeat expansion in ataxia patients from Hokkaido, the northernmost island of Japan. J Neurol Sci 2000; 175:45-51.

26 Cellini E, Nacmias B, Forleo P, et al. Genetic and clinical analysis of spinocerebellar ataxia type 8 repeat expansion in Italy. Arch Neurol 2001;58:1856-9.

27 Brusco A, Cagnoli C, Franco A, et al. Analysis of SCA8 and SCA12 loci in 134 Italian ataxic patients negative for SCA1-3, 6 and 7 CAG expansions. J Neurol 2002;249:923-9.

28 Tazon B, Badenas C, Jimenez L, et al. SCA8 in the Spanish population including one homozygous patient. Clin Genet 2002;62:404-9.

29 Topisirovic I, Dragasevic N, Savic D, et al. Genetic and clinical analysis of spinocerebellar ataxia type 8 repeat expansion in Yugoslavia. Clin Genet 2002;62:321-4.

30 Izumi Y, Maruyama H, Oda M, et al. SCA 8 Repeat expansion: large CTA/ CTG repeat alleles are more common in ataxic patients, including those with SCA 6. Am J Hum Genet 2003;72:704-9.

31 Ranum LP, Moseley ML, Leppert MF, ef al. Massive CTG expansions and deletions may reduce penetrance of spinocerebellar ataxia type 8 [abstract]. Am J Hum Genet Suppl 1999;65:A466.

32 Jardim LB, Silveira I, Pereira ML, et al. A survey of spinocerebellar ataxia in South Brazil-66 new cases with Machado-Joseph disease, SCA7, SCA8, or unidentified disease-causing mutations. J Neurol 2001;248:870-6.

33 Sempere AP, Millan JM, Royo-Vilanova C, et al. [Type 8 spinocerebellar ataxia. A report of a family]. Rev Neurol 2001;33:150-2.

34 Diamond A. Close interrelation of motor development and cognitive development and of the cerebellum and prefrontal cortex. Child Dev 2000;71:44-56.

35 Schmahmann JD, Sherman JC. The cerebellar cognitive affective syndrome. Brain 1998;121:561-79. 